
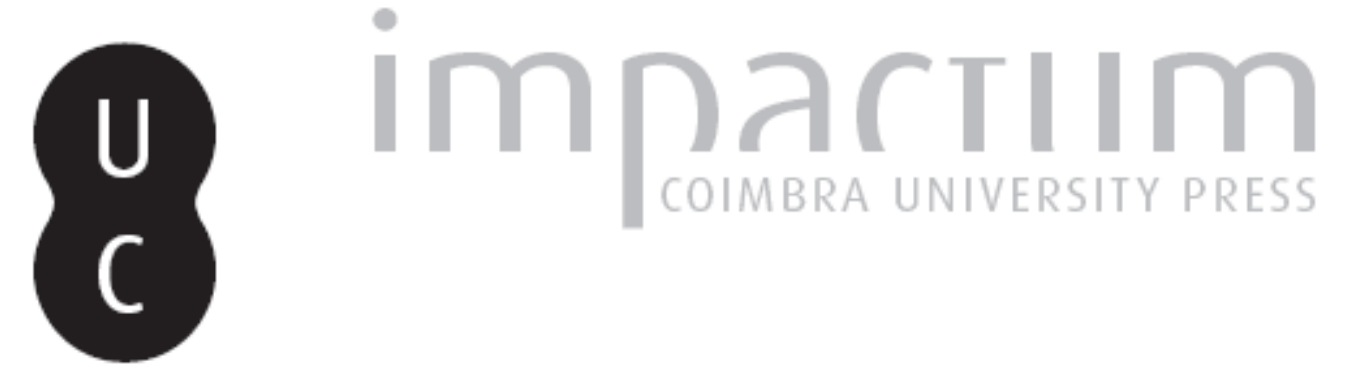

\title{
Riscos ambientais nas cidades e floresta urbana
}

Autor(es): $\quad$ Sarti, Antonio Carlos; Lombardo, Magda Adelaide

Publicado por: Associação Portuguesa de Riscos, Prevenção e Segurança

URL persistente:

URI:http://hdl.handle.net/10316.2/36111

DOI:

DOI:http://dx.doi.org/10.14195/1647-7723_17_22

Accessed : $\quad$ 26-Apr-2023 13:20:30

A navegação consulta e descarregamento dos títulos inseridos nas Bibliotecas Digitais UC Digitalis, UC Pombalina e UC Impactum, pressupõem a aceitação plena e sem reservas dos Termos e Condições de Uso destas Bibliotecas Digitais, disponíveis em https://digitalis.uc.pt/pt-pt/termos.

Conforme exposto nos referidos Termos e Condições de Uso, o descarregamento de títulos de acesso restrito requer uma licença válida de autorização devendo o utilizador aceder ao(s) documento(s) a partir de um endereço de IP da instituição detentora da supramencionada licença.

Ao utilizador é apenas permitido o descarregamento para uso pessoal, pelo que o emprego do(s) título(s) descarregado(s) para outro fim, designadamente comercial, carece de autorização do respetivo autor ou editor da obra.

Na medida em que todas as obras da UC Digitalis se encontram protegidas pelo Código do Direito de Autor e Direitos Conexos e demais legislação aplicável, toda a cópia, parcial ou total, deste documento, nos casos em que é legalmente admitida, deverá conter ou fazer-se acompanhar por este aviso.

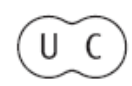




\section{territorium}

Riscos, Sociedade(s) e Segurança

Revista da Associação Portuguesa de Riscos, Prevenção e Segurança 2010 
territorium 17, 2010, 211-222

journal homepage: http://www.nicif.pt/riscos/Territorium/numeros_publicados

RISCOS AMBIENTAIS NAS CIDADES E FLORESTA URBANA ${ }^{1}$

Antonio Carlos Sarti

Universidade Estadual Paulista "Júlio de Mesquita Filho" - UNESP

acasarti@gmail.com

Magda Adelaide Lombardo

Universidade Estadual Paulista “Júlio de Mesquita Filho” - UNESP

lombardo@rc.unesp.br

\section{RESUMO}

Os materiais construtivos empregados na edificação da cidade e a configuração dos espaços verdes urbanos repercutem no aquecimento e na formação de micro-climas. A floresta urbana é apresentada como medida mitigadora, como conectora cultural e como ferramenta contra os riscos ambientais decorrentes de ocupação inadequada.

Palavras-chave: floresta urbana, risco ambiental, micro-clima urbano, cidade sustentável, cidadania.

\section{RÉSUMÉ}

Les matériaux de construction employé dans la construction de la ville et la configuration de l'impact des espaces verts urbains sur le chauffage et la formation de micro-climats. La forêt urbaine est présentée comme une mesure d'atténuation, telles que le connecteur culturelle et comme outil de lutte contre les risques environnementaux de l'utilisation inappropriée.

Mots clés: forêt urbaine, des risques environnementaux, les micro-climat urbain, la ville durable, la citoyenneté.

\section{ABSTRACT}

The construction materials employed in building the city and the configuration of urban green spaces have an impact on heating and in the micro-climate formation. The urban forest is presented as a mitigation measure, such as cultural connector and as a tool against the environmental risks due to the inadequate occupation.

Key words: urban forest, environmental risk, urban micro-climate, sustainable city, citizenship.

10 texto deste artigo corresponde à comunicação apresentada ao V Encontro Nacional e I Congresso Internacional de Riscos e foi submetido para revisão em 17-07-2009, tendo sido aceite para publicação em 30-09-2010.

Este artigo é parte integrante da Revista Territorium, n. ${ }^{\circ}$ 17, 2010, ${ }^{\circledR}$ RIscos, ISBN: 0872- 8941. 


\section{Introdução}

A urbanização definitiva da humanidade está coincidindo com o período em que o processo de aquecimento se torna mais agudo em decorrência da emissão de gases lançados na atmosfera, em grande parte, para atender à inesgotável necessidade de energia. Uma pequena parcela do território do planeta é responsável por significativa contribuição nas emissões. Os efeitos desse aquecimento nas cidades serão intensificados em função dos materiais construtivos, desenho, metabolismo, evidente prioridade dada a espaços construídos ante espaços não-edificados e das contradições da sociedade humana que inclui o alojamento de grande parcela da população de baixa renda em áreas sujeitas a riscos ambientais. Quer por características geológicas, geomorfológicas, pedológicas, climáticas ou do regime hídrico, áreas de risco deveriam ser convertidas em áreas non edificandi e recobertas de vegetação protetora.

No cenário de crise ambiental e de risco a que se submete a sociedade urbanizada, a floresta urbana é uma alternativa de mitigação relevante e estratégica. Ampliar as áreas verdes e azuis nas cidades criar condições para a sustentabilidade. Entretanto, é preciso alterar o paradigma que tem orientado a tradição utilitarista de ver a floresta urbana, passando a contemplar aspectos mais culturalistas. Da mesma maneira, a produção de resíduos vegetais e seu ingresso no metabolismo da cidade, podem criar fluxos circulares que também conectam as populações sob risco, constituindo-se em instrumento de gestão da cidade sustentável.

\section{Cidade sustentável}

“Por definição, as cidades não são ambientalmente sustentáveis. Seu território abriga uma densidade de população demasiado alta para se auto-sutentar." (Martínez Alier, 2007). Elas não são capazes de produzir tudo de que necessitam e exportam seus conflitos internos para muito além de seus domínios.

A importância do fenômeno da urbanização, acelerado dramaticamente durante o século $X X$, impôs a exigência de tratar a questão da cidade a partir de outro paradigma. O tema "crise ambiental" ganhou relevância e tem sido freqüente na agenda da cidade, sendo ali formatado e dali ganhando proeminência. A cidade foi o lugar para onde confluíram as informações e de onde irradiaram as formulações, sendo ela própria afetada pelo debate que proporciona. No momento em que mais da metade da população mundial habita cidades é premente desenvolver metodologias de planejamento e de governança que permitam melhorar as condições de vida e reduzir ou, utopicamente, anular, a pegada ecológica das cidades. No dizer de Rogers (2008, p.27): “o futuro da civilização será determinado pelas cidades e dentro das cidades", corroborando o ponto de vista.

O mesmo autor assevera que "metade da população urbana em crescimento estará morando em favelas sem água corrente, sem eletricidade, sem esgoto e quase sem esperança. Pelo menos 600 milhões de pessoas já vivem em ambientes urbanos que ameaçam a vida." (Rogers, 2008, p.27), expostas a riscos ambientais de diferentes fontes e magnitudes.

A gravidade do problema é associada ao metabolismo linear da cidade, quando seria ideal um metabolismo circular para proporcionar condições de sustentabilidade (fig. 1).
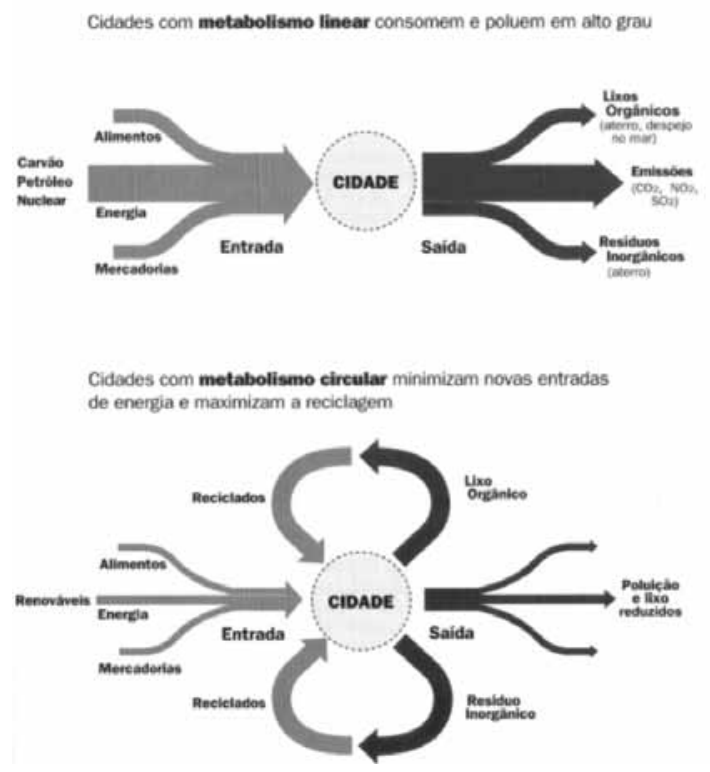

Fig. 1- Diagrama do metabolismo linear e do metabolismo circular, onde os resíduos são reintroduzidos (Fonte: Rogers, 2008).

A partir desta concepção o planejamento da cidade sustentável deve buscar os entrelaçamentos das relações entre os cidadãos, serviços, políticas de transporte e geração de energia, assim como o impacto que geram no espaço geográfico local e regional, otimizando os pontos nodais de todos os fatores.

Este ponto de vista propõe uma crítica ao modelo de forma expandida da cidade, de aplicação majoritária até o momento. Os mecanismos de expansão da mancha urbana são ditados pela lógica do mercado imobiliário provocando o avanço da área urbanizada sobre espaços ao redor. Avançando sobre áreas inadequadas para a edificação, aumenta a inversão de tecnologias da engenharia e maior quantidade de energia, transformando a zona rural próxima numa reserva de espaço para a expansão futura. Este modelo que parte do 
princípio da especialização dos espaços da cidade, tem exigido a implantação de infra-estrutura de transporte público, água, esgotos, telecomunicações, iluminação, distribuição de gêneros, áreas de lazer, postos de saúde, escolas, creches e demais equipamentos gerando uma estrutura complexa e dispendiosa e o constante deslocamento da população. Evoluído da reação ao ambiente insalubre das cidades no início da Revolução Industrial, o modelo hegemônico tornou-se inviável quando o atual pressuposto é encontrar um modelo de cidade que seja menos agressiva e melhor harmonizada com a vida de seus habitantes, com as finanças públicas e com o meio ambiente. 0 mais grave é que o modelo sob crítica ainda é o preferido nos países emergentes que estão entrando em acelerados processos de urbanização neste século. Desta maneira, proliferam as áreas de risco nas cidades.

Uma das alternativas mitigadoras é o investimento no modelo de cidade compacta, pois o adensamento não significa retornar aos padrões das velhas cidades. Segundo Rogers (2008, p. 33) “As cidades densas, através de um planejamento integrado, podem ser pensadas tendo em vista um aumento em sua eficiência energética, menor consumo de recursos, menor nível de poluição e, além disso, evitando sua expansão sobre a área rural (...) uma cidade densa e socialmente diversificada onde as atividades econômicas e sociais se sobreponham e onde as comunidades sejam concentradas em torno de unidades de vizinhança."

Outro fator é a constatação de que as cidades modernas, especialmente aquelas moldadas pelos CIAM - Congresso Internacional de Arquitetura Moderna foram dominadas pelo automóvel. O espaço da cidade deixou de ser prioritariamente de seu habitante para se converter num emaranhado de vias para o trânsito. 0 automóvel permitiu a fragmentação funcional, e, esta, a dissolução do campo (Franco, 2001, p. 63). Quanto maiores as cidades, mais compartimentadas as atividades e mais segregados seus habitantes. Paralelamente ao processo de urbanização que criará megacidades pelo processo de êxodo rural, na China, Índia ou Indonésia, o acesso dessa população ao automóvel acabará definindo o tipo de urbanização que ainda não é possível delinear. Para Martínez Alier (2007, p. 214) "Este [XXI] será o século da urbanização irreversível”.

Nesse aspecto, as construções que formam o tecido urbano, mesmo que isoladamente, precisam buscar atingir graus mais elevados de sustentabilidade empregando novas técnicas construtivas e novos materiais, além de alterar os conceitos subjacentes aos projetos.

A cidade é maior que a somatória de seus espaços. E o lugar da sociedade e suas contradições ocupa posição de eixo estruturante da produção cultural e dos movimentos de resistência e renovação, identificandose com a dimensão noótica, central na fig. 2. É o espaço da sociedade que o habita, transforma e por ela é transformado. Outros espaços - edificado e não edificado - lhes são contíguos e estão representados no mesmo nível e patamar de importância. O espaço edificado em uso - Utilis - comporta aquele ocupado pelas construções destinadas a atender às finalidades operacionais e funcionais. Constitui a infraestrutura para a oferta de serviços, produção, moradia e lazer, ainda obedecendo à lógica dos CIAM. $O$ espaço edificado sem uso - Non utilis - representa aqueles equipamentos urbanos que cumpriram a finalidade original e, no momento, se encontram fora de uso e constituem a mancha de espaços marrons no interior da massa de construções. Podem ser reciclados, reaproveitados para outras finalidades e são um claro exemplo da volatilidade de usos e significados associados aos espaços edificados na cidade. Eles estiveram associados a determinados ciclos e, na atualidade se encontram desconectados de valor estético, afetivo, histórico, cultural. Constituem uma reserva de espaços para os novos significados que a cultura criará, projetandoos para o futuro com outros usos. Enquanto isso não ocorre, estão isolados, abandonados, desconectados da vida da cidade. Os espaços verdes - Fito - constituem as áreas verdes da cidade. Elas podem ter sido criadas por força da aplicação do dispositivo legal ou decorrerem do crescimento da mancha urbana sobre as áreas rurais adjacentes. Também representam as áreas de fundos de quintais, fundos de vale, verde viário e todas as áreas onde a permeabilidade do solo foi mantida, mesmo para a implantação de pequenos jardins domésticos. São áreas que prestam relevante serviço ambiental ao garantirem condições de manutenção de avifauna e de manutenção do ciclo hidrológico no interior da cidade. Os espaços azuis - Hidro - representam as superfícies de água constituídas por nascentes, córregos, rios, lagos, represas, açudes, depósitos, chafarizes, bicas, orla marítima, praia, mangue e qualquer outro espelho d'água, associado ou não à vegetação. Cumprem papel fundamental na cidade sustentável, pois afetam tanto a percepção no campo cognitivo como nas condições de funcionamento físico do sistema urbano. As fontes de energia associadas a cada uma das categorias são de origem Natural ou Produzida pelo homem através de recursos tecnológicos. É o caso de fontes de energia como a solar, a geotérmica e eólica para a natural e elétrica obtida da transformação das energias contidas em outros recursos naturais, que aproveitam recursos hídricos, térmicos ou atômicos e a queima de combustíveis fósseis como petróleo, carvão, gás, biomassa e outras fontes em menor escala. 


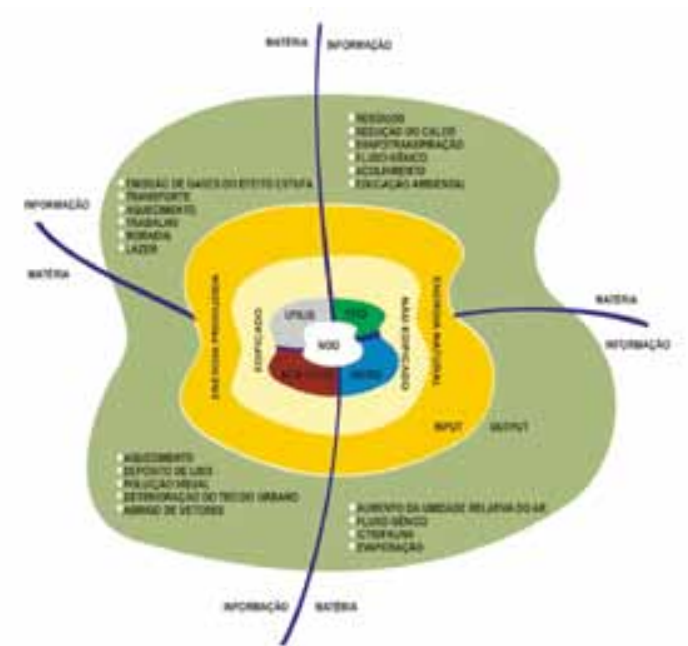

rıg. L - Uıagrama para a cıdade sustentavel onde a organızaçao interna da cidade é feita em igualdade de valores entre os elementos construídos e não-construídos, as fontes de energia (inputs) e os outputs gerados

O sistema urbano é alimentado por fluxos constantes de matéria e informação que se originam no exterior e se dirigem ao núcleo, perpassando os espaços edificado e não edificado. Matéria, energia e informação são os inputs ao sitema que modifica e é modificado pelo nooespaço, resultando em outputs de características positivas e negativas, diversos estados da matéria, em diferentes escalas de magnitude, variando no tempo e no espaço, potencializando ou reduzindo os conflitos, contradições, desigualdades e desnivelamentos inerentes à sociedade urbana, gerando qualidade de vida ou inviabilizando-a completamente.

O Brasil terá ao menos duas mega-cidades no século XXI - São Paulo e Rio de Janeiro. Para a realidade brasileira, entretanto, há outras percepções que precisam ser destacadas para ampliar a compreensão do que significa o desenvolvimento sustentável e seu rebatimento sobre as estruturas urbanas. MARICATO (2008, p. 70-81) expõe um QUADRO com oito pressupostos para reorientar a atuação democrática e sustentável. São eles: criar a consciência da cidade real e indicadores de qualidade de vida; criar um espaço de debate democrático de forma a possibilitar a visibilidade aos conflitos; realizar uma reforma administrativa; formar QUADRos e agentes para uma ação integrada; aperfeiçoamento e democratização da informação; desenvolver um programa especial para regiões metropolitanas; tomar a bacia hidrográfica como referência para o planejamento e gestão e, finalmente, formular políticas de curtíssimo, médio e longo prazos.

O planejamento da cidade sustentável implica na exigência cada vez maior de um conjunto mais amplo de indicadores reunindo os diferentes aspectos do desenvolvimento, contribuindo para a avaliação e formulação de novas estratégias, considerando os efeitos nos diferentes setores da sociedade, medindo e controlando as consequiências das políticas ambientais, dos programas e dos projetos de desenvolvimento sustentável.

\section{Natureza e cidade}

O processo de formação da cidade, desde seus primórdios, é indissociável das áreas naturais. 0 ambiente hostil que abriga as primeiras aglomerações cede espaço para a estruturação de dois grupos sociais: um que produz o excedente e outro que assume fazeres suportados por aquele. Complementam-se e subordinamse. No espaço natural organiza-se a atividade agrícola, conquistando áreas mais amplas. Próximo aos rios onde a disponibilidade de solos férteis e abundância de materiais com os quais edificar é abundante, a cidade se desenvolve e se constitui em ponto de convergência das rotas de transporte de mercadorias. Atraídas pelas trocas, as informações fluem. O poder encontra uma sede. A revolução se dá em decorrência da aceleração dos processos, na otimização dos recursos e nas trocas entre diferentes.

Jardins são implantados em espaços fechados, privados, e, na tradição ocidental, visavam desde ao suprimento de alimentos à demonstração de poder. Reforçam a percepção de controle da natureza e proporcionam conforto à moradia da elite. Associada a processos econômicos, sociais e políticos, a cidade ganha complexidade crescentemente, atraindo maior número de habitantes e atividades, dando e ganhando condições de produção e de trocas mais intensas, concentrando matérias-primas, energia e saberes múltiplos. 0 espaço da cidade se constitui no lugar de encontro dos diferentes e, neste aspecto cultural e antropológico, define-se com uma identidade. Gera, elabora e reelabora códigos, símbolos e signos particulares que the definem um modo de ser e resumem uma forma própria de entender e explicar o mundo. A influência da cidade sobre uma grande parcela do território acentua-lhe a função administrativa e o caráter de centro de poder político, econômico e religioso. Nascida do sucesso obtido na domesticação de plantas e animais, agora a cidade é o centro de decisão sobre o conjunto de um território, articulando-se ao espaço não edificado segundo seus interesses sub-ordenadores. A configuração dos espaços verdes obedece à mesma lógica utilitarista e maximizadora que organiza e constrói o espaço da cidade, consumindo um recurso natural escasso: o espaço natural que, ubanizado e/ou urbanificado, foi reificado.

Como "coisa" útil ao homem, associa-se a presença de árvores à purificação do ar e a criação de parques públicos ao combate das causas das epidemias. Segundo 
essa concepção, árvores e parques possibilitavam a circulação do ar na cidade e proporcionavam maior incidência de luz natural. Com a recorrente epidemia de cólera em Londres, facilitadas, principalmente, pelas condições de vida impostas à grande maioria da população, a observação atenta do uso da água servida ao público permitiu o mapeamento das ocorrências dos óbitos e a associação definitiva da epidemia às condições de qualidade da água destinada ao abastecimento público (JoHnson, 2008). As fontes de água passam a ser controladas e a idéias de um ambiente saudável se associa à qualidade da água. Desta maneira, passam a ser considerados insalubres as áreas alagadas (pântanos, brejos, mangues), margens de rios, córregos e lagoas, merecendo a ação que, amparada pelo salubrismo inquestionável, promove aterramento, retificação, represamento, drenagem, desvio e o aprofundamento ou assoreamento de canais. Identificada com o nocivo, o desprezível ou o inculto, a substituição ou até mesmo a supressão da vegetação nativa ainda presente, por outra mais exuberante, mesmo que exótica, é aceita como necessária. (SEGAWA, 1996, p. 217). O salubrismo está presente nos discursos e arrazoados oficiais quando da implantação de praças, jardins públicos, parques de diferentes dimensões e finalidades bem como faz parte do imaginário popular quando acionado para explicar ou dar sua percepção do ambiente natural ou do ambiente urbano dotado de elementos naturais (SEGAWA, 1996, p.67; Thоmas, 1996, p. 290-301 passim).

Neste ambiente artificializado, a introdução e manutenção da vegetação no ambiente urbano está intimamente relacionada aos aspectos positivos, principalmente quanto aos efeitos ornamentais, ao sombreamento, à redução da temperatura, ao aumento da circulação do ar, ao suprimento de energia e outros produtos alimentares ou ritualísticos. A ampliação da umidade relativa do ar, o suporte alimentar para espécies animais de pequeno porte, a função de fluxo gênico, a retenção de poeiras, a redução do ruído, o retardamento da chegada da precipitação até o solo e a redução do impacto dos pingos d'água sobre o solo, são benefícios percebidos bem mais tarde. A estes conjuntos de benefícios convencionou-se denominar "serviços ambientais".

As necessidades decorrentes do caos urbano já consolidado criariam as condições políticas para que os parques fossem concebidos, projetados e administrados como objetos urbanos aos quais se associa, principalmente, a função salubrista e, por decorrência, a de exercer o controle social sobre a população, mais especificamente sobre a população operária e de baixa renda (SARTI, 2001, p. 47), ao explorar a estrutura de atividades de lazer, bem ao estilo da visão instrumental dominante.
O ambiente urbano criado com a industrialização é marcado pelo desconforto de grande parte da população. A uma maioria, aglomerada em bairros periféricos desprovidos de infra-estrutura urbana e submetidos a uma política de máximo aproveitamento do espaço, tanto público como privado, impõe condições de vida adversas quando não totalmente insalubres. A uma minoria mais abastada, a cidade permite habitar, trabalhar, transportar-se e recrear-se com maior qualidade e variedade de oportunidades. Entretanto, aprisiona-os em condomínios-enclave, em edifíciosresorts, em avenidas congestionadas, em micro-climas saturados de poluição por gases e partículas ou sistemas de ar condicionado.

Dominadas pela poluição gerada com a queima de combustíveis fósseis para o aquecimento ou resfriamento e para a movimentação das máquinas, as cidades tornam-se ambientes vistos e interpretados como impróprios para a vida, contrapondo ao que se interpreta do campo como ambiente ideal para a se viver. Dessa contraposição estética, filosófica e também religiosa, desenvolve-se a idéia de que melhores condições sanitárias estão associadas à presença de árvores e de espaços onde elas possam ser plantadas, cultivadas e preservadas, envidando todos os esforços para ampliar a longevidade do conjunto dos indivíduos e não apenas daquelas reconhecidas como as mais velhas.

$\mathrm{Na}$ verdade, o que se está pressupondo é que o agravamento das condições climáticas exigirá mecanismos mais ágeis e participativos criando uma cultura de cuidar, de proteger, de perenizar as árvores, especialmente aquelas inseridas na malha urbana ou por ela incorporadas. A presença das árvores e seu apelo simbólico, aliados à presença de outras formas de vida animal e vegetal co-habitando e co-significando o mesmo meio ambiente, fortalecem os vínculos culturais provocando uma ampliação do sentido de cidadania.

\section{Espaços livres de acesso público}

É patente que há consenso quanto à necessidade de ampliar a oferta e qualificação de espaços verdes, quer por implantação de novos, quer por renovação, por reutilização de espaços urbanos degradados por outras atividades típicas da cidade industrial ou pelo desenvolvimento de novas tecnologias de implantação de áreas vegetadas em locais onde hoje as possibilidades ainda são experimentais ou remotas. O QUADRo I expõe tipologias de espaços verdes concebidos a partir de uma combinação matricial de fatores físicos, sociais, ambientais e econômicos que apontam para um socioecossistema sustentável, conforme defende FALcón (2007, p. 48). 
QuADRo I - Tipologias de espaços verdes de uma cidade sustentável de acordo com critérios de área, proximidade, benefícios psicossociais, contribuição ambiental e finalmente custos de manutenção em recursos econômicos e humanos. A terminologia "bolso" se refere a pequenas áreas próximas de residências (FALCón, 2007, p.48). Adaptado por Antonio C. SARTI, 2009.

\begin{tabular}{|c|c|c|c|c|c|c|c|c|c|c|c|c|c|c|c|c|}
\hline \multirow[b]{2}{*}{ Tipologia } & \multirow[b]{2}{*}{$\begin{array}{l}\text { Superfície } \\
\text { (ha) }\end{array}$} & \multirow[b]{2}{*}{$\begin{array}{c}\text { Secções } \\
(\mathrm{m})\end{array}$} & \multirow[b]{2}{*}{$\begin{array}{l}\text { Pessoas que } \\
\text { atende }\end{array}$} & \multirow[b]{2}{*}{$\begin{array}{l}\text { Raio de } \\
\text { influência } \\
\quad(\mathrm{km})\end{array}$} & \multirow[b]{2}{*}{$\begin{array}{c}\text { Cobertura } \\
\text { Vegetal } \\
(\%)\end{array}$} & \multicolumn{3}{|c|}{$\begin{array}{l}\text { Contribuição } \\
\text { psicossocial }\end{array}$} & \multicolumn{2}{|c|}{$\begin{array}{l}\text { Permite } \\
\text { Práticas? }\end{array}$} & \multicolumn{3}{|c|}{$\begin{array}{c}\text { Contribuição } \\
\text { Ambiental }\end{array}$} & \multicolumn{3}{|c|}{$\begin{array}{c}\text { Custo de } \\
\text { manutenção }\end{array}$} \\
\hline & & & & & & $\begin{array}{c}\text { Al } \\
t \\
a\end{array}$ & $\begin{array}{l}1 \\
1 \\
2\end{array}$ & $\begin{array}{l}\mathrm{B} \\
\mathrm{a} \\
\mathrm{i} \\
\mathrm{X} \\
\mathrm{a}\end{array}$ & $\begin{array}{l}\mathrm{s} \\
\mathrm{i} \\
\mathrm{m}\end{array}$ & $\begin{array}{l}N \\
a \tilde{~} \\
0\end{array}$ & $\begin{array}{l}A \\
\text { l } \\
t \\
a\end{array}$ & $\begin{array}{l}1 \\
l \\
2\end{array}$ & $\begin{array}{l}\mathrm{B} \\
\mathrm{a} \\
\mathrm{i} \\
\mathrm{X} \\
\mathrm{a}\end{array}$ & $\begin{array}{l}A \\
\text { l } \\
t \\
a\end{array}$ & $\begin{array}{l}1 \\
1 \\
2\end{array}$ & $\begin{array}{l}\text { B } \\
\text { a } \\
\text { i } \\
\text { X } \\
\text { a }\end{array}$ \\
\hline Periurbanos & +40 & 5.000 & 1.500 .000 & 10 & $60-80$ & $x$ & & & $x$ & & $x$ & & & & & $X$ \\
\hline Corredores & +20 & $500-1.000$ & 1.500 .000 & 10 & 80 & $x$ & & & $x$ & & $X$ & & & & & $X$ \\
\hline $\begin{array}{l}\text { Florestal } \\
\text { urbano }\end{array}$ & +3 & $500-800$ & 100.000 & 5 & 90 & $x$ & & & $x$ & & $X$ & & & & & $x$ \\
\hline Históricos & variável & variável & variável & variável & $40-80$ & & $X$ & & $x$ & & & & $X$ & $x$ & & \\
\hline Urbanos & $1-15$ & $300-500$ & $50-100.000$ & $1-2$ & $50-80$ & $x$ & & & $x$ & & & $x$ & & $x$ & $x$ & \\
\hline Lineares & $1-10$ & $25-100$ & $25-50.000$ & 5 & $40-70$ & $x$ & & & $x$ & & $x$ & & & $x$ & $x$ & \\
\hline Temáticos & variável & variável & 5.000 & variável & $60-80$ & & $x$ & & $x$ & & & & $x$ & $x$ & & \\
\hline Bolso & $0,2-0,5$ & $40-70$ & 6.500 & $0,25-0,50$ & $40-60$ & $x$ & & & $x$ & & & $x$ & & & & \\
\hline $\begin{array}{l}\text { Praças } \\
\text { arborizadas }\end{array}$ & $0,05-0,2$ & $25-50$ & 3.000 & $0,1-0,2$ & $40-60$ & & $X$ & & $x$ & & & $x$ & & & & $X$ \\
\hline $\begin{array}{l}\text { Verde de } \\
\text { acompanha- } \\
\text { mento de } \\
\text { vias }\end{array}$ & variável & variável & variável & variável & 90 & & & $x$ & & $x$ & & $x$ & & $X$ & & \\
\hline Jardineiras & - & - & - & - & - & & & $X$ & & $x$ & & & $X$ & & & \\
\hline
\end{tabular}

Considerando que a disponibilidade de espaços livres públicos deixa de ser um componente simbólico ligado à ostentação do poder ou de status social para assumir importância como indicador de qualidade ambiental que repercute no conceito de qualidade de vida é procedente a preocupação em estabelecer critérios com os quais comparar os dados elaborados em diferentes cidades e contextos.

Ressalva-se que muitos modelos são importados especialmente de países da Europa e dos Estados Unidos, e não refletem a realidade histórica de formação cultural e do processo de urbanização no Brasil, muito diferentes daqueles observados nos países desenvolvidos (SARTI, 2001). Entretanto, como países centrais do capitalismo, o acúmulo econômico permite construir uma cultura de relacionamento com as áreas livres públicas, inserindo-as definitivamente como exigência popular na perspectiva de garantia da qualidade de vida. O salubrismo é devidamente atualizado no discurso da mídia e no manejo dos símbolos definidores da imagem de saúde pública e da imagem de cidade, convertendo áreas verdes (árvores isoladas, hortas, quintais, praças, parques, bosques, cemitérios), convívio com animais (aves, insetos, mamíferos, peixes, répteis, batráquios, etc) recuperação de áreas degradadas, reciclagem de espaços urbanos (brownfields), restauração de monumentos históricos e outras alternativas de intervenção urbana em foco das políticas públicas sem, no entanto, renunciar definitivamente ao utilitarismo.
O pressuposto é que o agravamento das condições climáticas exigirá mecanismos mais ágeis e participativos para a implantação, uso e gestão de áreas verdes sendo premente encontrar alternativas para a consequente ampliação da geração de resíduos provenientes da floresta urbana.

Nas grandes concentrações urbanas estruturadas durante o século XX, o agravamento das condições meso e micro climáticas são resultantes da alta concentração de materiais de revestimento com propriedade conversiva da luz solar em calor, de gases e partículas poluentes e, ainda pior, da interação entre estes fatores. A presença da vegetação nas cidades, tanto em zonas centrais quanto na periferia, já não é só um fator de salubridade, assumindo importância estratégica para se garantir condições de vida com qualidade.

O conjunto da vegetação urbana é um componente do qual não se poderá mais prescindir dentro de um quadro de mudanças climáticas que está muito além do poder de controle intra-urbano.

Há espaços verdes urbanizados resultantes do lento processo de avanço do tecido urbano sobre a vegetação primitiva, presentes na forma de parques e praças densamente arborizados, fragmentos testemunhos da forma de cobertura pretérita ou mesmo com permanência de indivíduos isolados que resistem a ondas de ocupação. Há espaços que, tendo sido a vegetação primitiva totalmente removida por atividade agro-pastoril, 
sucede-a a urbanificação (SıILA, 1981, p. 372), resultando em áreas verdes totalmente implantadas, seguindo as diretrizes e intencionalidades de um projeto. Num meio ambiente extremamente agressivo, o metabolismo dos vegetais sofre estresse e o ataque de pragas é inevitável, fator que contribui para a baixa longevidade e, muitas vezes, para a exposição da população e seus bens, a perigos. Além disso, a atitude da população também atua de forma nociva quando não consegue perceber os benefícios diretos da presença da vegetação e muito menos as possibilidades dos benefícios indiretos assim que a planta está atingindo seu estágio de maior efetividade. Em conseqüência, pratica podas radicais e destruidoras de forma voluntária. Ou tolera a falta de aplicação da boa técnica por parte de agentes públicos ou seus prepostos, quer na condução do vegetal, quer na remoção integral.

Neste contexto, a adoção do conceito de floresta urbana ganha atualidade e relevância, pois aproxima elementos componentes até então vistos desconectados e por isso mais expostos aos agentes e comportamentos destruidores. A concepção de floresta urbana preconiza um sistema constituído por toda a vegetação e arborização urbana (Miller, 1997; Bradley, 1995, p. 4), enfatizando os usos e benefícios sociais que podem atingir o conjunto da população abrigada na cidade (CARTer, 1996; Hough, 2004; Falcón, 2007).

É preciso encontrar maneiras para construir novos significados para a vegetação no imaginário coletivo do citadino, ampliando a dimensão da cidadania. As relações devem ser mais culturalistas e menos utilitaristas.

O QuADRo II expõe o agrupamento das tradições das formas de ver a vegetação urbana desenvolvidas ao longo do tempo. Nosso entendimento é que estas visões não se anulam. Elas se complementam em superposições. A tradição utilitarista resiste ao avanço gradativo de outras tradições talvez pelo entendimento de que por serem os recursos naturais abundantes e inesgotáveis estão, portanto, disponíveis para serem sacados sem nenhum controle. Esta percepção expõe o anacronismo da cultura brasileira em relação aos padrões de solidariedade que têm norteado as políticas de sustentabilidade.

QUADRO II - Expondo o agrupamento das tradições sobre a forma de ver a vegetação urbana construídas ao longo do tempo e as superposições.

\begin{tabular}{|c|c|c|}
\hline $\begin{array}{l}\text { Tr a d i ç ã o } \\
\text { Utilitarista }\end{array}$ & $\begin{array}{l}\text { - Alimentos para o homem e animais } \\
\text { - Forragem (animais de tração e domesticados) } \\
\text { - Combustível (lenha para cocção) } \\
\text { - Abrigo (vestuário, construção civil) } \\
\text { - Ornamentação (embelezamento de ruas, praças, parques, jardins, quintais e outros espaços } \\
\text { públicos e privados) } \\
\text { - Temperos, produtos medicinais, ritualísticos e outros produtos não-madeireiros }\end{array}$ & $\begin{array}{c}\text { Para quê } \\
\text { serve }\end{array}$ \\
\hline $\begin{array}{l}\text { Tr a d i ç ã o } \\
\text { Ambientalista }\end{array}$ & $\begin{array}{l}\text { - Paisagismo (harmonização entre aspectos estéticos e serviços ambientais) } \\
\text { - Biodiversidade (atração e manutenção de aves, insetos, anfíbios, répteis e mamíferos) } \\
\text { - Energia (economia proporcionada aos sistemas de ar condicionado e calefação, controle das } \\
\text { disfunções do albedo) } \\
\text { - Bioindicadores (capacidade de reação a determinados poluentes do ar, produção de pólen) } \\
\text { - Assimilação de poluentes (retenção de partículas, metabolismo e fixação no solo) } \\
\text { - Combate/controle de processos erosivos (atenuante de impacto das chuvas, redução da } \\
\text { velocidade de escoamento) } \\
\text { - Proteção e perenização de fontes de água (garantia da qualidade das nascentes e margens de } \\
\text { cursos d'água) } \\
\text { - Compostagem (reintrodução de nutrientes no solo) }\end{array}$ & $\begin{array}{c}\text { Para quê } \\
\text { serve } \\
+ \\
\text { serviços } \\
\text { ambientais }\end{array}$ \\
\hline $\begin{array}{l}\text { Tr a d i çã o } \\
\text { Culturalista }\end{array}$ & $\begin{array}{l}\text { - Educacional (fonte de informação, simbolismo, trilhas de interpretação, educação ambiental) } \\
\text { - Pobreza (pertencimento, demarcação de territórios, acessibilidade, amenização do sentimento } \\
\text { de marginalidade, prevenção de riscos) } \\
\text { - Estética (novos significados associados à vegetação, longevidade, contraste com edifícios, } \\
\text { quebra do mito da natureza controlada) } \\
\text { - Acolhimento (sensação de hospitalidade ou agressividade, desenvolvimento do turismo urbano, } \\
\text { topofilia ou topofobia, revitalização de espaços urbanos degradados; } \\
\text { - Saúde pública (efeitos proporcionados pelo acesso). }\end{array}$ & $\begin{array}{c}\text { Para quê } \\
\text { serve } \\
+ \\
\text { serviços } \\
\text { ambientais } \\
+ \\
\text { significados }\end{array}$ \\
\hline
\end{tabular}


Os múltiplos papéis da vegetação na cidade

A presença das árvores no ambiente urbano decorre da estreita relação do homem com a natureza mediada por configurações culturais. Ao longo do processo as transformações se processam condicionadas pelas alterações que também ocorrem no conjunto da sociedade. Desta maneira, delineia-se uma trajetória que remete a três tradições de formas de ver a vegetação: utilitarista, ambientalista e culturalista.

A Tradição utilitarista compreende os benefícios materiais, os usos marcadamente definidos pelo critério de utilidade que possam ter os componentes do vegetal. Atendem à pergunta 'Para quê serve?', isto é, acabam funcionando como um insumo ou meio para solução imediata de alguma necessidade básica: alimentação (do homem e de animais domesticados), energia (combustível para aquecimento, resfriamento e cocção), abrigo (vestimenta e casa) e outros usos como cerimonial, medicinal, ritualístico e como temperos.

$\mathrm{Na}$ Tradição ambientalista a percepção dos benefícios ambientais passa a ser mais evidente quando considera os fatores biológicos decorrentes da presença da vegetação nas cidades, introduzida e conduzida a partir do reconhecimento de que se está tratando com um vegetal, ser vivo, em interação com o ambiente artificializado da cidade, abrigo e habitat do homem. Esta fase ainda subordina a vegetação urbana ao interesse da sociedade humana, embora a visão sistêmica apresentese como modelo de explicação baseado nas relações e interdependências. Ao tornar evidentes os atributos positivos da presença das árvores na cidade, entende estes benefícios do ponto de vista das atividades humanas no ambiente urbano: habitação, produção, transporte e lazer. Há um apelo ao lado simbólico da construção de espaços arborizados, públicos e privados, relacionandoos com saúde, liberdade, segurança e qualidade de vida, destacando-se certa tendência à antropomorfização do vegetal (atribuir-lhe formas e sentidos humanos como cabeça, corpo e membros; gratidão, dor, sede, medo, alegria, audição, tato, dentre outros). 0 paisagismo admite que há um jogo de complementaridade e de diálogo entre o projeto das construções e a vegetação que o ambientará. A biodiversidade é a resultante do emprego de diversas espécies vegetais que são capazes de dar suporte e atrair a avifauna e insetos. O grau de sombra proporcionada por uma copa bem desenvolvida e conduzida é o fator mais visível e percebido numa cidade de clima tropical. A sombra afeta diretamente a incidência de sol nas áreas pavimentadas com asfalto e concreto, contribuindo para regular a temperatura e este é um fator de maior ou menor uso de energia para aquecimento ou refrigeração. Bioindicadores são aqueles vegetais com sensibilidade a determinados componentes poluentes da atmosfera permitindo que se avalie a qualidade do ar em função de sua tolerância a determinados parâmetros como poluentes e poeiras em suspensão, e emissão de gases. A assimilação de poluentes é uma característica da vegetação pois faz a ligação entre solo e atmosfera. Tudo que acontece num sistema repercute no outro. Neste sentido, uma árvore metaboliza o poluente $\mathrm{e}$ remete-o ao solo. Há espécies de árvores que têm no sub-solo a mesma biomassa produzida na copa, sendo as raízes uma espécie de caixa de armazenamento de energia a ser reutilizada na primavera. 0 solo tem papel determinante na manutenção e eficácia desta capacidade de processar os poluentes. Também em relação ao solo, os processos erosivos também são fatores de risco e se instalam ou são impactados por ação do acelerado processo de ocupação urbana. As árvores podem proteger o solo, quer como atenuadora do impacto da chuva, quer como fixadora do solo por ação do sistema radicular, quer como redutora da velocidade com que a água da precipitação chegará ao solo. Quando a floresta urbana conecta áreas localizadas na periferia ou constitui Áreas de Preservação Permanente, exerce influência sobre a capacidade de vazão dos sistemas de drenagem envolvidos pela malha urbana e, neste sentido atua como protetora e perenizadora das fontes de água. A compostagem tem sido a forma de reciclagem dos restos vegetais provenientes de podas ou do caimento de folhas, frutos, flores e galhos mais comumente empregada, muito embora ainda esteja longe de atingir um índice que seja condizente com a importância de tal prática.

A Tradição culturalista decorre do conceito de sustentabilidade, que tem a visão sistêmica em sua base, mas, amplia o horizonte de tratamento da floresta urbana, a exemplo do que ocorreu em inúmeras outras áreas do conhecimento. A partir da Rio 92, quando o conceito de sustentabilidade ultrapassa o ponto de inflexão, ocorre ampla assimilação de seus postulados que alimentam um novo paradigma baseado no equilíbrio dinâmico das vertentes: socialmente justo, economicamente viável e ambientalmente suportável contextualizados por mecanismos de participação efetiva nos processos decisórios e na manutenção dos sistema político aberto às inovações. Já não cabe compreender a vegetação nas cidades a partir de sua utilidade material ou dos benefícios ambientais ou biológicos. Abandonam-se os critérios vistos isoladamente e insere os valores culturais e de convivência simbiótica entre as esferas biótica, abiótica e noótica. "Se está produciendo la transición entre una sociedad preocupada por el consumo y la explotación y otra que da prioridad a un futuro sostenible." (Hough, 2004, p.6). A inserção Educacional, a partir desta concepção, não será obtida apenas com a implantação de placas de identificação, embora elas ainda sejam fundamentais para oferecer informações básicas. Está sendo muito bem aceito pela sociedade o uso de refúgios 
florestais ou de fragmentos de mata incrustados na malha urbana para a organização de trilhas de interpretação da natureza, explorando diferentes temas surgidos a partir do conhecimento mais aprofundado destes locais. Dado ao processo de urbanização ocorrido no Brasil, as várzeas foram utilizadas para alojar população de baixa renda expondo a risco de inundação grandes contingentes populacionais. 0 mesmo ocorreu com a utilização de áreas com ocorrência de solos inadequados para a construção como turfoso e colapsível. Também se utilizou terrenos sobre antigos aterros de resíduos sólidos industriais e de restos de construção (bota-fora). Em função do maior risco, o preço se torna mais baixo e acessível às camadas mais pobres da população. A floresta urbana deveria ser priorizada para áreas com estas características, organizando a ocupação e garantindo maior segurança à cidade, ao mesmo tempo em que garante os serviços ambientais e os ganhos de qualidade de vida que se estendem ao coletivo. 0 aspecto estético decorre de a vegetação dar a dimensão humana da cidade, uma vez que é tão componente vivo quanto o homem. Edifícios são abióticos e tendem a ser cada vez mais altos, concentrando recursos, pessoas, serviços, energia e resíduos. Exercem um papel simbólico do poder financeiro e tecnológico. Extrapolam a referência da escala humana. Inibem, amedrontam, ameaçam e afastam a maioria, tornando-se peças de uma composição do espaço urbano espetacularizado. A circulação das imagens geradas a partir dos objetos construídos segundo esta lógica reforça internamente a perpetuação do modelo econômico que despreza a função social da propriedade e concentra os benefícios nas mãos de poucos cabendo, à maioria, a coadjuvância de expectador. É um modelo feito por e para uma minoria que conhece as tecnologias e que as impõe sem reverência. Quanto ao acolhimento, Grinover (2007) afirma que "Exprime não apenas a infraestrutura formal de recebimento, mas dá a tônica aos códigos de acolhimento, essência da hospitalidade e do turismo." Sob o ponto de vista da hospitalidade quando em interação com o lugar e com o lazer, mesmo que se preserve a herança do atributo de controle social, a abertura à receptividade, acesso a informações, sinalização, mobiliário, abordagem, programação e composição paisagística, entre outros fatores, devem provocar no cidadão usuário a percepção do acolhimento, que é a premissa para a hospitalidade. Logo, a exploração das interfaces lugar-lazer-hospitalidade pode abrir possibilidades inúmeras para inovar ou enfatizar soluções de gestão urbana e do turismo. Quando a humanidade alcança o índice de mais de $50 \%$ da população total do planeta e o país ultrapassa os $80 \%$ vivendo em cidades, é o mesmo que dizer que a referência comum a todas as pessoas é a urbanidade. Ao estar numa cidade que não é de origem, a sua, se espera que estejam à disposição serviços e espaços públicos de padrão correspondente àquela, ressalvadas as proporções de escala. 0 acolhimento, a hospitalidade, os elementos da paisagem, o tratamento humano, independem de capacidade de investimento e dependem muito mais da construção de consensos em torno de um projeto anfitrião comum, que envolva a comunidade. Outra externalidade positiva da floresta urbana refere-se à saúde pública uma vez que a oferta de áreas verdes na forma de parques públicos e praças, mesmo que não sejam de grandes dimensões, implicam em efeitos sobre a saúde de jovens e crianças. A oferta sistêmica de oportunidades de práticas ao ar livre atinge o conjunto da população por possibilitar atividades físicas, mesmo que com o único objetivo de combater ao sedentarismo. Entretanto, a cidade moderna, além do sedentarismo, também tem na obesidade infantil outro problema difícil de ser enfrentado. $E$ as soluções não estão somente no controle e na reeducação alimentar, pois elas, mesmo quando são praticadas, precisam estar conjugadas com outras medidas educativas. Crianças exploram o lúdico, a brincadeira, a liberdade de inventar a forma de fazer um movimento. Num parque ou numa praça, os espaços deveriam ser estimulantes para a liberdade e não para fazer o que todos fazem, em brinquedos fabricados e pré-programados a partir de um pressuposto de gosto. Este é um novo enfoque para o uso de áreas verdes públicas que se refere à prevenção, à fruição e ao exercício da liberdade.

\section{Floresta urbana e resíduos}

A presença da vegetação sob a forma de floresta urbana vem a se constituir em elemento indispensável à vida na cidade. Já está abandonada a concepção de que a vegetação é apenas um componente embelezador. Ou que sua presença supre funções para as quais não se encontrou outro fornecedor, tais como as biológicas. 0 crescimento descontrolado das cidades, a concentração de população e recursos e os problemas atmosféricos que ganham maior relevância e magnitude no ambiente urbano, obrigam a compreensão da floresta urbana como componente de um sistema complexo, onde todas as funções se complementam. A presença das árvores no ambiente urbano é um elemento de sustentação da vida urbana com qualidade.

Mas também é inegável que pelo fato de a floresta urbana ser constituída por seres vivos dos quais se espera longa e saudável existência, há permanente produção de biomassa e/ou suporte para a dinâmica ecológica. A produção de resíduos é permanente, depositando-se sobre canteiros, gramados, calçadas, telhados, calhas, ruas, sarjetas, asfalto e outros pavimentos, superfícies lisas e rugosas. Levados pelo vento ou pela chuva, podem se tornar um grande problema, provocando entupimento de condutos em edifícios residenciais, comerciais, industriais, hospitais, equipamentos 
sociais públicos ou privados (escolas, creches, presídios) ou equipamentos de infra-estrutura urbana como bueiros e galerias de águas pluviais. Nos leitos dos rios, entrando em decomposição, suas fibras mais resistentes servirão como suporte para aglutinar outros resíduos orgânicos e inorgânicos, formando, em muitos casos, tampões e represamentos que reduzem a velocidade ou facilitam o transbordamento. Todos os processos se confluem: solo impermeabilizado implica em maior quantidade de água escoada superficialmente; que arrasta maior quantidade de resíduos; que entulha mais depressa os canais; que tem reduzida a vazão; que não suporta a chegada de mais água, em maior velocidade. A conseqüência será o inevitável alagamento, enchentes, refluxo em sistemas de drenagem urbana, perdas materiais e, muitas vezes, vidas.

\section{Quatro Rs}

Portanto, deve-se aplicar ao resíduo produzido pela floresta urbana o mesmo princípio dos quatro Rs preconizado para os resíduos industrializados:

Reduzir - A redução implica numa atitude preventiva do planejamento priorizando o uso de espécies mais adequadas ao local onde serão plantadas, considerando as características fenológicas e o ciclo de vida da planta. Em se tratando de árvores, a perspectiva de manejo deve ser medida em décadas. Já que a geração de resíduos é inevitável, a estratégia de redução implica em fazer a escolha da árvore criteriosamente correta aplicando uma matriz de variáveis físicas, biológicas, sociais e culturais. Também afeta a redução a permanência pelo maior tempo possível, fazendo com que vegetal cumpra seu ciclo de vida. Substituições constantes geram maior quantidade de fitomassa. Fatores intervenientes nesta performance e eficácia, ao longo de décadas, tais como podas, combate a pragas, períodos de longa estiagem ou abundância de água, indícios de falta de nutrientes, acidentes com intempéries, acidentes urbanos (trânsito, fogo, fixação de objetos, etc.), simbioses, tratamentos a que venha a ser submetido o componente da paisagem, devem ser monitorados.

Partindo-se do princípio de que quanto mais qualificadas são a escolha e a gestão dos indivíduos ou conjunto deles, o monitoramento on line não estará longe de ser uma excelente ferramenta. Constituir bancos de dados utilizando SIG - Sistema de Informações Geográficas, embora seja uma tecnologia plenamente dominada e conhecida com muitas experiências já realizadas, ainda está muito longe da realidade de grande parte dos municípios. 0 mais comum e acessível tem sido a implantação de bancos de dados utilizando planilha Excel, alimentada periodicamente a partir de relatórios e inspeções de campo. A operacionalidade deste sistema exige equipe especializada e organização do fluxo das informações entre o gerenciador do banco de dados e a equipe de campo. O maior problema é o caminho inverso, isto é, partir de uma informação captada no Banco de Dados e dirigir-se a um determinado indivíduo ou grupo deles. 0 uso de etiquetas de alumínio presas com prego de aço no tronco, contendo um número que referencia o objeto no cadastro, tem sido alvo de vandalismo, o que impede a localização. Portanto, onde o sistema existe, é possível encontrar expertise a respeito. Entretanto, ainda é um procedimento pouco desenvolvido, contribuindo, para isto, além de fatores orçamentários, a visão de prioridade derivada da concepção utilitarista. Como as "utilidades" têm valor de mercado menor que os encargos que acarretam, pouco se percebe dos benefícios proporcionados por uma floresta urbana devidamente planejada e manejada.

A tecnologia RFID - Radiofrequency Identification vem se colocar como um fator facilitador para diversas necessidades. Para o controle do vandalismo, pois a tag (transponder, um chip conectado a uma antena) utilizada, no formato de um prego, é de cor escura e se mimetiza com as muitas cores das cascas das espécies mais empregadas (fig. 3). Sua localização é possível com a utilização de um leitor manual que aciona o chip e acessa as informações lá existentes, pois é passiva.

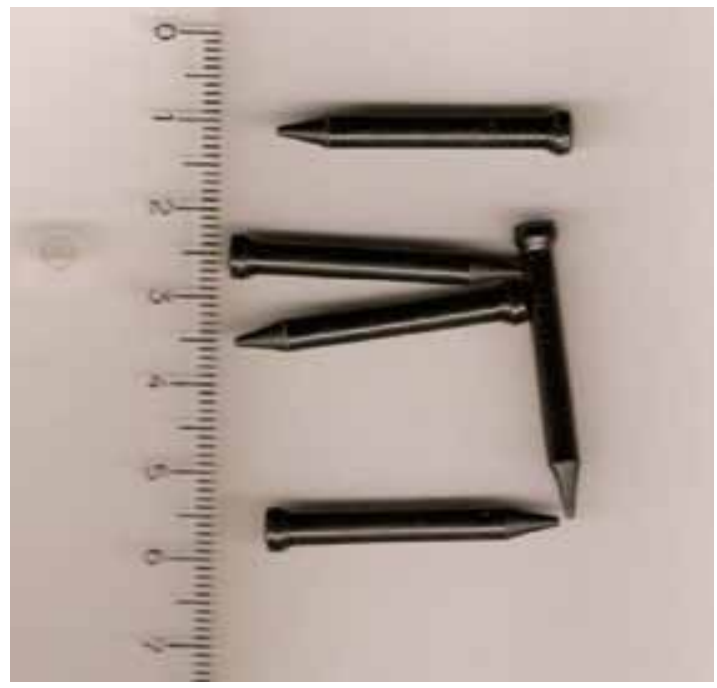

Fig. 3 - imagem da tag (conjunto chip e antena) em forma de prego, construído em resina biorresistente. Fonte: Antonio C. Sarti, 2009.

A durabilidade do material é grande, pois é construído com resinas biorresistentes. Para a utilização como ponto de apoio para roteiros turísticos ou de Estudo do Meio, a tag deve ser ativa, sendo capaz de armazenar maior número de informações que são lidas com o leitor manual, podem ser acessadas, atualizadas e regravadas. Outra solução é associar a etiqueta passiva com o Banco de Dados portátil num computador de mão e, desta maneira, ampliar as possibilidades de 
acessos, links, imagens, textos, tabelas, fotos, e outras informações digitais. Os maiores obstáculos para que a tecnologia ganhe mais espaço é o custo do sistema, hoje na casa dos US\$2.00/unidade e o fato de as soluções operacionais disponibilizadas não terem universalidade, isto é, são desenvolvidas por fabricantes diferentes, com diferentes tecnologias e linguagens próprias. A tendência é o barateamento para a faixa de centavos de dólar e a universalização dos sistemas, pois outros setores que demandam grande quantidade de etiquetas tag estão buscando soluções na mesma linha de exigências. Sem dúvida, abre-se um setor de possibilidades inovadoras ligadas ao uso turístico e para a Educação Ambiental, além de aumentar a eficiência dos processos de gestão, segundo o paradigma culturalista.

Não será impossível desenvolver um sistema com etiquetas ativas de forma que haja emissão de informações on line, permitindo a leitura e acompanhamento em tempo real. Nas atuais condições os preços de aluguel de bandas de satélite tornam os custos proibitivos. Porém, há uma tendência de barateamento à medida em que novos usos vão surgindo e, no nosso caso, quando se perceber que as árvores cultivadas na floresta urbana podem ser agregadas ao mercado consumidor de produtos diretos tangíveis (madeira, frutos, folhas, raízes, flores, suporte de fauna, etc) e produtos diretos intangíveis (redução da temperatura, aumento da umidade relativa do ar, componente estético, informações fenológicas e botânicas, monumentalidade), será possivel tratar a questão com outro enfoque.

Reutilizar pressupõe que a floresta urbana é um ato deliberado e decorrente do processo de urbanificação. A utilização dos resíduos resultantes da fenologia caracteriza-se como um re-uso, uma re-utilização. $\mathrm{Na}$ verdade, os resíduos podem ser percebidos como potencialmente incorporadores de algum conhecimento popular ou não - ou tecnologia. Ao serem transformados, fazem o trânsito do resíduo, de objeto descartado e inservível, para outro objeto a ser empregado na decoração de ambientes, adorno corporal, matéria prima para artesanato, suvenires, recursos para expressão artística, material pedagógico, brinquedos, enfeites domésticos, brindes e outros infinitos usos, ganhando novo significado e status.

0 efeito estético, quando se constitui na motivação do emprego de determinada espécie, pode ser entendido como um uso dos atributos de beleza, com predomínio das qualidades imateriais, sendo os resíduos materiais decorrentes e posteriores à utilização original. Ambos, imaterial e material, são estratégias de reificação da floresta urbana, guardando intrínseca sintonia com o modo capitalista de produção e apropriação do fitoespaço urbano. Um exemplo pode se encontrado junto a locais destinados à atividade turística onde o tratamento paisagístico tem por finalidade emoldurar ou criar um ambiente estético mais familiar aos visitantes. Para isto aplica espécies de uso recorrente em muitos países e regiões, baixando a diversidade e introduzindo elementos "poluidores" na paisagem, em nome do "conforto" simbólico do visitante.

Plantas já existentes na paisagem urbana e enraizadas em locais que possam comprometer sua atividade biológica, devem ser remanejadas para outros locais onde possam sobreviver de maneira adequada, caso a espécie e porte assim permitam. Do contrário, o espaço deve ser adequado à arvore de forma a garantir que possa cumprir seu ciclo vegetativo.

O uso de biomassa vegetal para obtenção de energia é uma forma possível de reutilização para a qual se dispõe de tecnologia. A obtenção de calor pode ser intensificada produzindo-se briquetes a partir de resíduos como folhas, galhos, aparas de gramados, serragem e todo tipo de resíduos triturados em pedaços compatíveis com o objetivo de obter um cilindro com cerca de 12 $\mathrm{cm}$ de diâmetro e cerca de $40 \mathrm{~cm}$ de comprimento. A compactação sob pressão dos resíduos a partir de volumes muito grandes para volumes muito pequenos gera calor suficiente para liberar a lignina, que funciona como elemento colante à medida que esfria, garantindo a forma e a duração do briquete por um determinado tempo, ante certas condições de umidade e temperatura. Pode ser utilizado em lareiras, com recursos aromáticos, e em fornos de lenha, substituindo-a. 0 briquete pode ser utilizado também como fonte de calor na co-geração de energia termoelétrica, utilizando a infra-estrutura da região que possui inúmeras usinas de açúcar e álcool com sistemas de co-geração a partir da queima da palha e do bagaço da cana-de-açúcar. Queimar não seria o melhor uso, mas é muito melhor a queima controlada e que gera energia elétrica do que a queima descontrolada que gera desconforto aos moradores da cidade. Um re-uso potencial que está em vias de ocorrer em escala industrial é a utilização da lignocelulose na obtenção de açúcares que, depois de fermentados, produzirão etanol. A produção de objetos que possam ser absorvidos por outras atividades urbanas tais como o paisagismo também é viável.

Reciclar implica em explorar as características dos resíduos florestais para obtenção de derivados que possam ser empregados no ciclo vegetativo. Através do processo de compostagem é possível obter composto orgânico a ser introduzido em canteiros na forma de cobertura, fertilizante, retentor de umidade e protetor de partículas do solo, restabelecendo o ciclo dos nutrientes e do carbono. Para a obtenção do composto orgânico, há necessidade de área, equipamento e equipe treinada, o que encarece e dificulta a montagem da infra-estrutura necessária. A solução alternativa é depositar o material orgânico sobre o solo e contar com a ação dos micro-organismos que farão 
a decomposição gradualmente, incorporando os nutrientes ao solo e, durante o processo, garantirão excelente nível de umidade. Também pode-se obter produtos com características fúngicas, aplicáveis no manejo das plantas, especialmente no início do ciclo vegetativo.

Retardar exige desenvolver estratégias de ampliação da longevidade dos indivíduos (árvores) ou dos seus conjuntos (bosque, floresta, mata-galeria, fragmento) componentes do ambiente urbano. Ao desenvolver usos das fibras das quais são constituídos todos os vegetais, o efeito no meio ambiente urbano é imediato, pois deixam de entrar no sistema de limpeza urbana no ato em que são produzidos. Incorporar uma técnica ou tecnologia implica em dar um uso que retarda, por muitos anos, o descarte enquanto resíduo, retendo o $\mathrm{CO}_{2}$ e contribuindo para a qualidade de vida. A ampliação da percepção dos benefícios diretos e indiretos da floresta urbana, quer por seus atributos material ou imaterial, atua como fator de longevidade. Devem ser estimuladas as pesquisas e esforços no desenvolvimento de metodologias de planejamento que permitam colocar a vegetação nos locais mais adequados a cada indivíduo, maximizando suas potencialidades de serviços ambientais e de produção de resíduos aproveitáveis. Também devem ser desenvolvidas tecnologias de monitoramento com a utilização de softwares e chips que levem ao armazenamento de informações e controle do histórico de manejo. 0 diagnóstico da fitossanidade com utilização de ferramentas não-destrutivas como ultra-som, assim como tratamento curativo de deficiências nutricionais ou decorrentes do ataque de pragas também devem ser incrementados para ampliar o tempo de permanência da floresta no ambiente urbano, em condições saudáveis.

Estes aspectos podem ser considerados na elaboração de políticas públicas que relacionem a sustentabilidade do ambiente urbano e a construção de um modelo de cidade que esteja mais próximo do cidadão e da cidadania.

\section{Conclusões}

A floresta urbana é uma alternativa para a mitigação dos efeitos do aquecimento que tende a ser mais agudo nas cidades. 0 planejamento da cidade sustentável não pode prescindir da floresta urbana tanto pelos efeitos no micro-clima como pelo ordenamento da ocupação de espaços impróprios para edificação, como pela criação de fluxos de reintrodução dos resíduos que podem incluir as populações menos privilegiadas e mais submetidas a risco.

Contribuindo para ganhos de qualidade ambiental a partir de seu papel como regulador do sistema, a floresta urbana contribui para melhorar as condições de qualidade de vida no ambiente urbano, tornando possível estender os ganhos aos visitantes. Este novo resultado, derivado dos entrelaçamentos dos fluxos, pode adicionar conteúdos à educação ambiental, à ampliação da autoestima e ao incremento das finanças públicas.

\section{Bibliografia}

Bradley, G. A. (ed.) (1995) - Urban forest landscapes: integrating multidisciplinary perspectives. Seatle: University of Washington Press, 222p.

CARTER, E. J. (1996) - El potencial de la silvicultura urbana en los paises en desarrollo: conceptos. Santiago: FAO - Organización de las Naciones Unidas para la Agricultura y la Alimentación, 96p.

FALCón, A. (2007) - Espacios verdes para una ciudad sostenible: planificación, proyecto, mantenimiento $y$ gestión. Barcelona: Gustavo Gili, 175p.

Franco, M. de A. R. (2001) - Planejamento ambiental para a cidade sustentável. São Paulo: Annablume; Blumenau: Edifurb, 296p. (2 ed.).

GrinOver, L. (2007) - A hospitalidade, a cidade e o turismo. São Paulo: Aleph, 191p.

Hough, M. (2004) - Naturaleza y sociedad: planificación urbana y procesos ecológicos. Barcelona: Gustavo Gili, 315p.

JoHnson, S. (2008) - O mapa do fantasma. Rio de Janeiro: Zahar, 272p.

LıMA, A .M. L. P.. et al. (1994) - "Problemas na utilização de termos como espaços livres, áreas verdes e correlatos". In: Anais... Congresso Brasileiro de Arborização Urbana, 2, São Luis (MA). Imprensa EMATER/MA, p. 539-553.

MARICATO, E. (2008) - Brasil, cidades: alternativas para a crise urbana. Petrópolis: Vozes, 204p.

Martínez Alier, J. (2007) - O ecologismo dos pobres: conflitos ambientais e linguagens de valoração. São Paulo: Contexto, 379p.

Miller, R. W. (1997) - Urban forestry: planning and managing urban green spaces. 2 ed. New Jersey: Prentice Hall.

Rogers, R. (2001) - Cidades para um pequeno planeta. Barcelona: Gustavo Gili, 180p.

Thomas, K. (1996) - O homem e o mundo natural. São Paulo: Cia. das Letras.

SARTI, A. C. (2001) - Propostas para delimitação de um parque periurbano para a cidade de Rio Claro (SP). Universidade Estadual Paulista, Rio Claro. $283 \mathrm{f}$.

Segawa, H. (1996) - Ao amor do público: jardins no Brasil. São Paulo: Nobel, 255p.

SıIVA, J. A. (1981) - Direito urbanístico brasileiro. São Paulo: Revista dos Tribunais, 617p. 